\title{
The Role of Motivation and Desire in Explaining Students' VR Games Addiction: A Cognitive-Behavioral Perspective
}

\author{
Xuesong Zhai $\mathbb{D}^{1,2}$ Fahad Asmi ${ }^{1}{ }^{3},{ }^{3}$ Jing Yuan, ${ }^{4}$ Muhammad Azfar Anwar, ${ }^{5}$ \\ Nabia Luqman Siddiquei, ${ }^{6}$ Intikhab Ahmad $\mathbb{D D}^{3,7}$ and Rongting Zhou $\mathbb{D}^{3,8}$ \\ ${ }^{1}$ College of Education, Zhejiang University, Hangzhou, China \\ ${ }^{2}$ Anhui Province Key Laboratory of Intelligent Building and Building Energy Savings, Anhui Jianzhu University, Hefei, China \\ ${ }^{3}$ University of Science and Technology of China, Hefei, China \\ ${ }^{4}$ Quality-Oriented Education Research Center, Anhui Xinhua University, Hefei, China \\ ${ }^{5}$ Shenzhen University, Shenzhen, China \\ ${ }^{6}$ Virtual University of Pakistan, Lahore, Pakistan \\ ${ }^{7}$ Bahria University Islamabad Campus, Islamabad, Pakistan \\ ${ }^{8}$ Key Laboratory of Immersive Media Technology (Wanxin Media), Ministry of Culture and Tourism, \\ Hefei, China
}

Correspondence should be addressed to Intikhab Ahmad; intikhabahmad@mail.ustc.edu.cn and Rongting Zhou; rongting@ustc.edu.cn

Received 21 January 2021; Revised 7 March 2021; Accepted 9 April 2021; Published 8 May 2021

Academic Editor: Ali Ahmad

Copyright $\odot 2021$ Xuesong Zhai et al. This is an open access article distributed under the Creative Commons Attribution License, which permits unrestricted use, distribution, and reproduction in any medium, provided the original work is properly cited.

\begin{abstract}
Virtual Reality games create an interactive platform for gaming and education for young people. While some longitudinal study has studied the beneficial effects of VR games on learning, the problematic use of VR games by a significant number of learners has become increasingly serious. The current study investigated the mediating effect of behavioral desire and moderation of cyber aggression on consumers' VAD, which contributes to behavioral and psychological urge to use VR games. Data are from 367 VR games users collected. Findings suggest that behavioral desire influences addictive behavior in the presence of a positive flow experience. Furthermore, theoretical and practical implications in the context of VR-based games are also discussed in this current research.
\end{abstract}

\section{Introduction}

Virtual Reality (VR) games consist of devices that monitor the behavior of users and react to the sensory world, intended to replicate the physical world. In recent innovations, VR has been made available to a broad customer market and has widened its coverage to cover fitness, arts, and entertainment as commercial value. It is also believed that the entertainment industry will adopt VR technology more frequently in the near future. Besides, scientific research and theorizing of VR culture are expanding along with VR technology advances [1]. Moreover, the Games industry is intending to adopt immersive technology and it will be a game-changer in the games industry.
The early traces of technology of VR (previously known as Sensoromoa) dates back to the 1960s, a period in which color TV was the most recent advance in major media production. Video game companies were brought to the retail market in the mid-1990s with the first generation of consumer-oriented products, although it took many decades to grow [2]. Though recently the trend of VR use is changed to infotainment and entertainment and it is getting wide attention from the consumers. The global film industry has cleverly adapted its technical innovation to plan, create, and generate content that can provide its customers with the greatest economic and psychological gains [3]. In different sectors, a parallel increase in technical growth can be observed [4]. Ineke also concluded VR as an important aspect of the future entertainment environment. It must be 
remembered that even though various fields of education and connectivity have been established by the VR industry, entertainment is still a core element of technical interaction in the face of diverse intentions. Most consumers, therefore, seem to know VR as an interactive platform irrespective of their particular intent [5].

Furthermore, many of the educational intuitions intend to develop a Virtual Learning Environment (VLE) for better results than the traditional way of learning. Moreover, previous studies used the VR tool as a motivational tool for education. Merchant et al. also stated, for example, that VR increases the capacity of young people in schools and colleges to read [6]. Furthermore, Bergin counters the previous statement that the VR environment encourages the students' learning ability because of the media richness of the VR environment. Moreover, Educational games will have a positive impact on the users. Previous papers suggest that VR brain games enhance the cognitive skills of the students more than the traditional way of schooling [7]. Because of the broad geographic penetration and business value, VR technology is now a strategic informatics and entertainment weapon, and many sectors, including e-commerce, real estate, and sport, consider VR technology as an open platform [8]. In the year 2020, the VR industry is projected to hit US\$ 120 trillion [9]. The existence of VR is thus observed to increase over the ITC spectrum [10]. Authors claim that the transition from passive to active in associated sectors will make it easier for relevant stakeholders to reach optimum economic and psychological benefit [11]. In this current study, authors have assumed that VR users will harm their behavior, specifically addictive behavior among users. Therefore, the objective of the current study to emphasize VR driven consumers' addictive behavior, which can help map and recommend preventive measures to avoid addiction and reduce the impact of overuse of VR-based games.

\section{Literature}

Numerous learning experiences have been provided through virtual reality (VR). VR will potentially bring tremendous possibilities in the future and is hence a tool to be regarded and investigated at considerable length. VRs are being used as virtual learning environments (VLE) in which students can communicate with others while performing a variety of tasks [12]. You may even learn new techniques, including spatial socialization, networking, data processing, and even new linguistic capacities. It is a heuristic method for engaging students through real-time and creative concepts. It took several years to reach the consumers' use. In the early 1960s, the first VR technology was introduced due to the high price it was not possible to use for entertainment purposes but for military and medical training, whereas in the mid-1990, it was introduced to mass markets by the Gaming Industries and it can be easily found anywhere in the market with little price.

Previous studies suggested that the companies need to work on the display and the quality of the function to enhance the users of VR gadgets, and it is the need of time to reduce the price so that layman can easily use for their daily uses. Flow is defined by a battle between real and actual challenges [13].
Moreover, a previous study indicated that once the user plays best in both physical and mental states, they usually forget entirely about their surroundings even the time they are passing [14]. "The users work in his/her maximum capacity when they are inflowing. The person works at maximum capacity when they are in flow. If challenges start to surpass skills, one becomes alert first and then anxious; if skills continue to exceed challenges, one relaxes first and then becomes bored" [15]. Furthermore, the dimension of the theory of flow is divided into nine elements: clear purposes, feedback in time, the balance of challenges and skills, integration of behavior and consciousness, removal of interference in consciousness, freedom of control, loss of self-awareness, time-conscious abnormalities, and its purposive knowledge [14]. Over time, this same behavior will cause a person to worry for a moment and then instantly relax in a state of flow [16]. Studies show that perceived gratification occurs in a state of flow [17]. Persons that can interact with the technology and believe that time flows while focusing on its output are more likely to reach a flow state. In reality, when people have fun, a feeling of distortion is especially common [18]. It is assumed that flow in the games will lead to the desire to play more games frequently. Prior research suggested that social games are involved in flow and the fact that flow leads to the overuse of Internet applications that causes addiction to the games [19].

Compulsive gaming has become a significant and growing social issue since the advent of online video games. The prevalence rates for teenagers range between five and ten percent, depending on the definition of gaming addiction $[20,21]$. As a "condition to further research" in the Diagnostic and Statistical Manual of Mental Disorders (DSM-5), the American Psychiatric Association (APA) agreed that game dependence might pose a serious threat to adolescent psychosocial development [22]. Addiction is thus a condition of uncontrollable conduct that induces the mind to perform recurring tasks in a way that neglects to do its everyday life acts. Zilberman, Yadid, Efrati, and Rassovsky stated that addiction might impact the formulation of both positive and negative life events [23]. Furthermore, in the review of addictions and related psychological disorders [24], E-sport (or e-game) is a phenomenon that simultaneously has the same effect as a type of entertainment and sport and is experienced both online and offline [25]. Kuss and Lopez-Fernandez pointed out that digital gaming is another inherently addictive topic.

Gong, Zhang, Cheung, Chen, and Lee stated that online games, social networks games, or Massively Multiplayer Online Role Play Games (MMORP) are the core elements of addictive behavior. Similarly, a previous paper by Mancini, Imperato, and Sibilla stated that VR self-Discrepancy, Avatar identification will also lead to addictive behavior. Furthermore, users wanted to enhance the skills and earn more online outfits and types of equipment which cause them serious addictive behavior.

\section{Theoretical Framework}

Research on Virtual Reality is ongoing through the advancement of VR-Technologies and the growth of the VR- 
Industrial, including architecture [26], medicine [27], and training [28]. The TAM was the most narrowly modified model for customers' expectative and system interventions [29]. In multiple experiments, VR technology was used to integrate external influences. Theories of technology acceptance focus primarily on advantages and ignore important consumer risk assessments [30, 31]. The TAM2 [32], UTAUT [33], and UTAUT2 [34] are examples of how models for functional adaptation are built over time. Nonetheless, no behavioral model relevant to technology was appropriate for demonstrating the darker side of technical advancement. In this research, the high media richness appreciates the addictive aspect of consumers of VR games. The cognitive-behavioral model was renamed by (Davis) to "Problematic Internet Use."

The Cognitive Behavioral Model is identified as the problematic IT Use (PIT). In this model, user's cognitions as the main reason for abnormal behavior. Davis concentrated on "pathological Internet usage" and "dysfunctional elements" of maladaptive cognitions. He also explained his concept of two forms of PIU: basic and common. The particular PIU refers to the inappropriate use of the Internet or the reliance on a certain form of utility, such as gaming, the use of personal content, stocks traders, or auction services. People with generalized PIU frequently spend more time on quantities of online chat and e-mail without any reason. They are possibly unadjustable and prefer social contact online in the real world. Davis did not consider the use of the Internet as a source of anxiety and depression but believed PIU as the product of maladaptive, psychologically induced cognitive processes. Caplan, based on the cognitivebehavioral model [35], claims of the problem use of the Internet includes maladaptive cognitions and abnormal behavior and the renaming of "pathological Internet use" to "problematic Internet use." Prior studies demonstrate the potential insight for understanding the role of dilemma IT use of the cognitive-behavioral model $[36,37]$. As a result, this theory has been used more and more to investigate various aspects of addictive activity such as online gaming [19], online trading [36], and overuse of the Internet [38]. Authors also presume and try to validate that the cognitivebehavioral paradigm is sufficient to describe addiction to VR games. While the cognitive-compliance approach offers a logical basis for the definition of addiction, clear variations need to be taken into account to achieve a better interpretation of features in various contexts [39].

3.1. Flow as Construct. Flow has been described as an ideal experience, the best emotions, the most satisfying human life experiences that derive from people's perceptions of difficulties and abilities in specific situations [13, 40]. Csikszentmahalyi developed the theory of flow, which describes a condition of concentration or complete absorption with activity and the situation [41]. Moreover, cognitive absorption is characterized as a state of deep involvement with IT based on flow theory [42]. Research indicates that cognitive absorption adversely affects the conduct of users in the use of the target information system. Csikszentmihalyi explains the enjoyment of the citizens who do a thing that gives little clear intrinsic incentive but is highly satisfying and fulfilling. Such behaviors were inherently motivational and their optimum experience was classified as "flow" [43]. The sport is inevitable and the flow interaction of excellence is play [43]. Moreover, flow is characterized as an "experience of the highest," as it is a concentrated psychological condition of pleasure (Enjoyment) and productivity $[15,42]$. Performing time flies may be the most striking aspect of the flow experience. This finding was introduced into the flow analysis by Csikszentmihalyi when he suggested that a person's knowledge of time is a predictor of flow. If a work experience is strong and equal to the degree of competence of the individual and whether they are, therefore, in the flow stage, their subjective perception of time is less than the objective time that has elapsed [44]. Moreover, pleasure (enjoyment) motivates the curiosity about the behavioral desire to show certain talent to others [45]. In addition, previous studies indicate that heavy behaviors and loss of self-regulation have a beneficial impact on the addiction to the online game [46]. For instance, from a games perspective, too much involvement in flow through being overabsorbed and involved can damage children as they may obsess the state of pleasure but ignore self-care and interpersonal relations [47]:

H1: individuals' enriched flow experience in VR encourages consumers to have VR games addictive behavior

$\mathrm{H} 2$ : individuals' enriched flow experience in VR encourages consumers to have a behavioral desire to use VR games

3.2. Behavioral Desire. It can be argued that strong desires can be pleasurably experienced if no negative consequences are expected, but if potential benefits are also linked by guilty feelings, a desire may be less pleasurable and even strained. Andrade suggests that mental images are emotive. This claim is reinforced by the idea that neural sensitization mechanisms can switch between love and openness to addictive behaviors [48]. Rose et al. found some evidence that Website (online games) approaches may affect adolescents' diet and physical behavior. This can be partly because of the interaction's uncertainty. Such improvements are not, however, necessarily maintained over the medium or long term [49]. Furthermore, two forms can be conceptualized for a user's desire: the desire for the actions of a person and a desire for the behavior [46]. The second type of want (desire) is a mutual desire rooted in an individual social group's selfconcept and represents the drive to socialize with social group members $[46,50]$. In addition, previous studies indicate that heavy behaviors and loss of self-regulation have a beneficial impact on the addiction towards technology [46].

H3: behavioral desires of VR game users motivate consumers to have VR games addictive behavior

$\mathrm{H} 4$ : behavioral desire of VR games mediates the relationship between flow experience and VR game addiction 
3.3. Cyber Aggression. Cyber aggression has been described as a repetitive course of action involving intentional or unwanted interpersonal violence mediated by ICT in an attempt to threaten, insult, harass, and/or endanger the target $[51,52]$. The self-perceived effect on teenagers is also an issue in most conceptions of cyber aggression. Recent studies have found that cyber aggression is not inherently harmful or disturbing, while other studies have shown that cyber aggression intervention can cause significant physical, mental, educational, and social consequences [53]. The young person may contribute to understanding these high rates of development and their initial capacity to awareness of the moral, social, and legal consequences of cyber aggression behaviors [54]. Previously published research articles stated that aggression is directly related to game addiction. Similarly, previous studies also suggest that cyber aggression has nothing to do with game addiction behavior in real life. Formerly, Kim, Namkoong, Ku, and Kim reported Craig's report stated that low self-esteem and negative evaluation of oneself are the good predictors of game addiction and the total time spent on playing video games. Similarly, it is assumed that Cyber Aggression can potentially have a great impact on behavioral desire and simultaneously have influential power on users' addictive behavior towards the game addiction, specifically VR-based games.

H5: the essence of Cyber aggression moderates the relationship between VR games flow experience and its addictive behavior

\section{Materials and Methods}

The study tested the hypothesized model by using the Preacher and Hayes process macro (Model 4). The further methodological aspects are discussed in detail in the following subsections. Although, in the field of quantitative research, the applied mathematical research holds a variety of approaches, i.e., [55, 56]. However, behavioral analysis is mostly comprised of behavior modeling and hypothesisbased study, as observed in the current research.

4.1. Instrument. The quantitative research approach adopted the existing sources of literature to make the results credible and valid for further study. Three-item scale for CA is adapted from Zhang and Sun, a five-item scale for EJ is adopted from Ghazali et al., and the three-item scale for TD is adopted from Im and Varma, whereas for BD authors adapted a three-item scale from the study of Hsieh and Liao. Similarly, author's adapted five-item scales for CG from Shapka and Maghsoudi and GA were measured by a threepoint scale as suggested by Gong, $\mathrm{Yu}$, and Luqman to emphasize customer VR addiction. To measure each model, a Likert scale (1-Highly Disagree and 5, Highly Agree) was adopted.

4.2. Data Collection. The data were gathered from the user of VR games who approached through the social networking sites (SNS) (in particular Facebook). The authors took the stance of basic random sampling as (1) over the world leading VR-based Facebook pages; as authors not considered any of the controlled variables, i.e., gender and age group. The only condition authors followed is to find potential candidates for the survey who have not restricted themselves to accept unknown friend requests.

It is important to note that SNS limited and suspended many data collector accounts during this data collection process as SNS has stringent rules on submitting requests from friends within a certain amount of time, particularly the data collection period of seven months (mid of February to mid of September 2020). Each of the respondents initially been contacted with a brief introduction and purpose of the study. Moreover, to enhance the data response, the authors announced that the prize amount range from $\$ 1$ to $\$ 10$ in the form of bitcoin. The history of individuals consuming VRbased games has been researched to check possible sample candidates. The remaining sample was submitted by the only respondents who had a positive response. The authors also assume that the obtained sample is optimal for the analysis. A total of 600 participants were invited for the survey. However, 470 responses have been received after 30 consecutive weeks. During the initial data securitizing, 103 responses were eliminated for the incomplete responses. As a result, only 367 responses were able to be examined. For the nonresponse biases, authors inspected the initial subset of 30 participants with the later participants. In this way, the early and the later responses help authors to conclude that there is no evidence of nonresponse biases found. A short descriptive profile of the user of the VR-based game is shown in Table 1.

\section{Findings}

To examine the reliability and validity of all constructions and models, factor analysis was performed. Factor loading for each variable, Cronbach-alpha $(\alpha)$, composite reliability, and extracted average variance (AVE) of each variable computed, as shown in Table 2.

In the next phase of analysis, the structural model is built from the data with the help of SPSS-AMOS. The initial and the second-order index values of the model noted in the satisfactory range as listed in Table 3 . The root means estimate noted over the continuum of 0.050 to 0.052 as within a suggested acceptable range $[57,58]$. In addition, the chisquares observed within the range of 3.436-4.319 in both of the cases of CFA (first and second-order) and the model, are as listed in Table 3. Moreover, all other fitness indices are listed in Table 3.

The Variance Inflation Factor (VIF) was estimated for all constructs to analyze the multicollinearity effect. The VIF values recorded in Table 4 were less than the 10 cut-off values as recommended by Hair et al. [59] Specifically, it ranged from 1.287 to 1.451 . Therefore, in the current study, multicollinearity was not a problem. The common method bias effect was measured to ensure the findings were reliable as the data collection monoprocess was observed. The Harman single method score was determined as a part of dimension 
Table 1: Demographics of respondents.

\begin{tabular}{|c|c|c|c|}
\hline Characteristic & Detail & Frequency & In percentage \\
\hline \multirow{2}{*}{ Gender } & Male & 294 & 80.11 \\
\hline & Female & 73 & 19.89 \\
\hline \multirow{4}{*}{ Frequency of playing VR games (in a week) } & Once & 19 & 05.17 \\
\hline & Two or three times & 43 & 11.72 \\
\hline & Four or five times & 196 & 53.41 \\
\hline & More than five times & 109 & 29.70 \\
\hline \multirow{3}{*}{ The most appealing attribute of VR games } & Immersion & 154 & 41.96 \\
\hline & Interactivity & 117 & 31.88 \\
\hline & Sensory feedback & 96 & 26.16 \\
\hline
\end{tabular}

TABLE 2: Reliability analysis of the collected survey.

\begin{tabular}{|c|c|c|c|c|c|}
\hline Construct & Items & Loadings & CR & CA & AVE \\
\hline \multirow{5}{*}{ Cyber aggression (CA) } & CG1 & 0.879 & 0.923 & 0.923 & 0.706 \\
\hline & CG2 & 0.866 & & & \\
\hline & CG3 & 0.858 & & & \\
\hline & CG4 & 0.828 & & & \\
\hline & CG5 & 0.767 & & & \\
\hline \multirow{5}{*}{ Enjoyment (EJ) } & EJ1 & 0.872 & 0.888 & 0.882 & 0.615 \\
\hline & EJ2 & 0.801 & & & \\
\hline & EJ3 & 0.790 & & & \\
\hline & EJ4 & 0.743 & & & \\
\hline & EJ5 & 0.706 & & & \\
\hline \multirow{3}{*}{ Cognitive absorption (CA) } & CA1 & 0.899 & 0.924 & 0.765 & 0.802 \\
\hline & CA2 & 0.894 & & & \\
\hline & CA3 & 0.893 & & & \\
\hline \multirow{3}{*}{ Time distortion (TD) } & TD1 & 0.804 & 0.835 & 0.906 & 0.628 \\
\hline & TD2 & 0.791 & & & \\
\hline & TD3 & 0.783 & & & \\
\hline \multirow{3}{*}{ Behavioral desire (BD) } & BD1 & 0.867 & 0.885 & 0.900 & 0.718 \\
\hline & $\mathrm{BD} 2$ & 0.845 & & & \\
\hline & BD3 & 0.831 & & & \\
\hline \multirow{3}{*}{ VR game addiction (GA) } & GA1 & 0.768 & 0.791 & 0.746 & 0.559 \\
\hline & GA2 & 0.767 & & & \\
\hline & GA3 & 0.706 & & & \\
\hline \multicolumn{6}{|c|}{ Maximum variance explained is $33.074 \%$} \\
\hline
\end{tabular}

TABLE 3: Fitness indices of the proposed model.

\begin{tabular}{lccc}
\hline Fitness indices & First order & Second order & Proposed model \\
\hline Chi-square & 625.366 & 688.084 & 820.596 \\
Degree of freedom & 182 & 188 & 190 \\
Chi-square/degree of freedom & 3.436 & 3.660 & 4.319 \\
GFI & 0.947 & 0.942 & 0.929 \\
AGFI & 0.927 & 0.922 & 0.905 \\
NFI & 0.956 & 0.951 & 0.942 \\
TLI & 0.959 & 0.956 & 0.945 \\
CFI & 0.968 & 0.964 & 0.955 \\
RSMEA & 0.050 & 0.052 & 0.058 \\
\hline
\end{tabular}

Note. ${ }^{* * *}=$ Significance level of $0.001,{ }^{* *}=$ Significance level of $0.01,{ }^{*}=$ Significance level of 0.05 .

reduction [60]. The highest variance reported for a single factor in the current analysis was 33.074 percent, suggesting that neither any proposed construct controlled the overall model variance and common method biasness is not the problem in this study. The following section will lead to the testing of the proposed hypotheses.
For examining the proposed model, SPSS-Process Macro was used as suggested by Preacher and Hayes, and the study examined the mediating effect of behavioral desire in case of the relationship between the flow experience and VR-based games addiction among youth. The results concluded that the richness of flow experience has the potential to increase 
TABLE 4: External reliability analysis.

\begin{tabular}{|c|c|c|c|c|c|c|c|c|}
\hline Construct & Mean (SD) & VIF & CG & EJ & $\mathrm{CA}$ & TD & $\mathrm{BD}$ & GA \\
\hline CG & $4.047(0.606)$ & 1.287 & 0.840 & & & & & \\
\hline EJ & $3.865(0.738)$ & 1.451 & $0.293^{* *}$ & 0.784 & & & & \\
\hline CA & $3.239(0.804)$ & 1.218 & $0.164^{* *}$ & $0.362^{* *}$ & 0.895 & & & \\
\hline TD & $3.800(0.815)$ & 1.233 & $0.271^{* *}$ & $0.334^{* *}$ & $0.326^{* *}$ & 0.792 & & \\
\hline $\mathrm{BD}$ & $3.578(0.814)$ & 1.420 & $0.430^{* *}$ & $0.442^{* *}$ & $0.163^{* *}$ & $0.222^{* *}$ & 0.845 & \\
\hline GA & $3.683(0.667)$ & - & $0.479^{* *}$ & $0.339^{* *}$ & $0.153^{* *}$ & $0.193^{* *}$ & $0.402^{* *}$ & 0.747 \\
\hline
\end{tabular}

TABLE 5: Mediation analysis by using bootstrapping with the sampling size $=5000$.

\begin{tabular}{|c|c|c|c|c|c|c|c|c|c|c|}
\hline Hyp & IV & $\mathrm{M}$ & DV & Effect of IV on M & Effect of $M$ on DV & Direct $\left(c^{\prime}\right)$ & Indirect $(\mathrm{a} * \mathrm{~b})$ & Total effect (c) & $95 \%(\mathrm{Cl})$ & Mediation \\
\hline $\mathrm{H}$ & FL & $\mathrm{BD}$ & GA & $0.501^{* * *}$ & $0.277^{* * *}$ & $0.202^{* * *}$ & $0.139^{* * *}$ & $0.341^{* * *}$ & $(0.109,0.172)$ & Supported \\
\hline
\end{tabular}

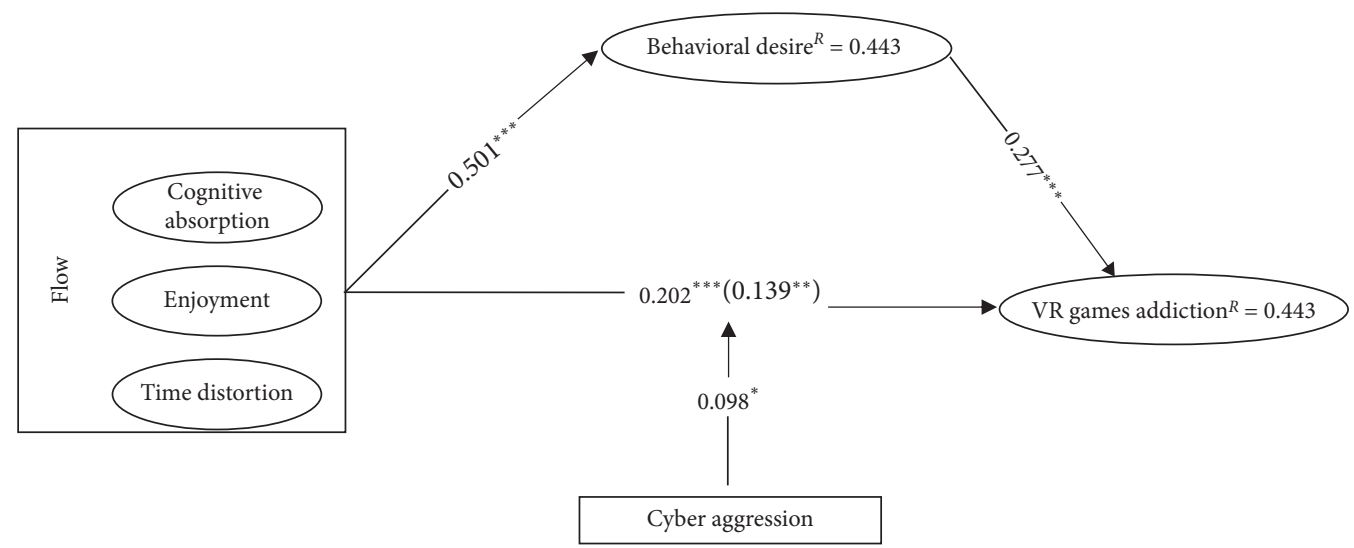

FIgURE 1: Graphical explanation of proposed model of the study.

VR game addiction among youth $(\mathrm{H} 1: \beta=0.501, p \leq 0.001)$ and also helps to elevate the behavioral desire among youth to get involved in VR games $(\mathrm{H} 2: \beta=0.139, p \leq 0.01)$. Moreover, the findings also concluded that the behavioral desire also positively affects VR games addiction among users, which can potentially lead towards valuable practical implications (H3: $\beta=0.277, p \leq 0.001$ ).

In the meanwhile, the mediating effect of behavioral desire is also noted as significant, which statistically underlines the partial mediating behavior of behavioral desire in the currently proposed settings. Particularly, the bootstrapping results in the tabular format are listed in Table 5 and shown graphically in Figure 1.

The hierarchal regression analysis was adopted to test the proposed moderating effect of Cyber aggression on the association between enriched flow experience and VR games addiction among youth. The findings are listed in Table 6 below. The statistical findings revealed that the presence of cyber aggression strengthens the relationship between flow experience and VR games addiction among users ( $\mathrm{H} 5$ $\beta=0.098, p \leq 0.05$. Further, the slope test examined the strength and nature of the moderating effect, as shown in Figure 2.
TABLE 6: Moderating effect of cyber aggression over the association between flow experience and VR games addiction.

\begin{tabular}{lccc}
\hline Construct & Model 1 & Model 2 & Model 3 \\
\hline Flow (FL) & $0.341^{* * *}$ & $0.185^{* * *}$ & $0.219^{* * *}$ \\
Cyber aggression $(\mathrm{CA})$ & & $0.470^{* * *}$ & $0.226^{* * *}$ \\
FL $*$ CA & & & $0.098^{*}$ \\
$F$ & 97.927 & 113.081 & 167.111 \\
$R^{2}$ & 0.090 & 0.253 & 0.256 \\
\hline
\end{tabular}

\section{Discussion and Conclusion}

In this current study, the authors concluded that this study implicates all the stakeholders (i.e., Education, Entertainment, and Infotainment). Authors found that flow creates a high level of addiction among the users when it mediates with the behavioral desire, which means that behavioral desires need to be more bifurcate. Likewise, in previous studies, VR is widely used for entertainment purposes rather than educational purposes; therefore, addiction through behavioral desire also supports the stance of addiction behavior studies. It is worth mentioning that there are dark aspects in VR that need to be sorted out. For entertainment 


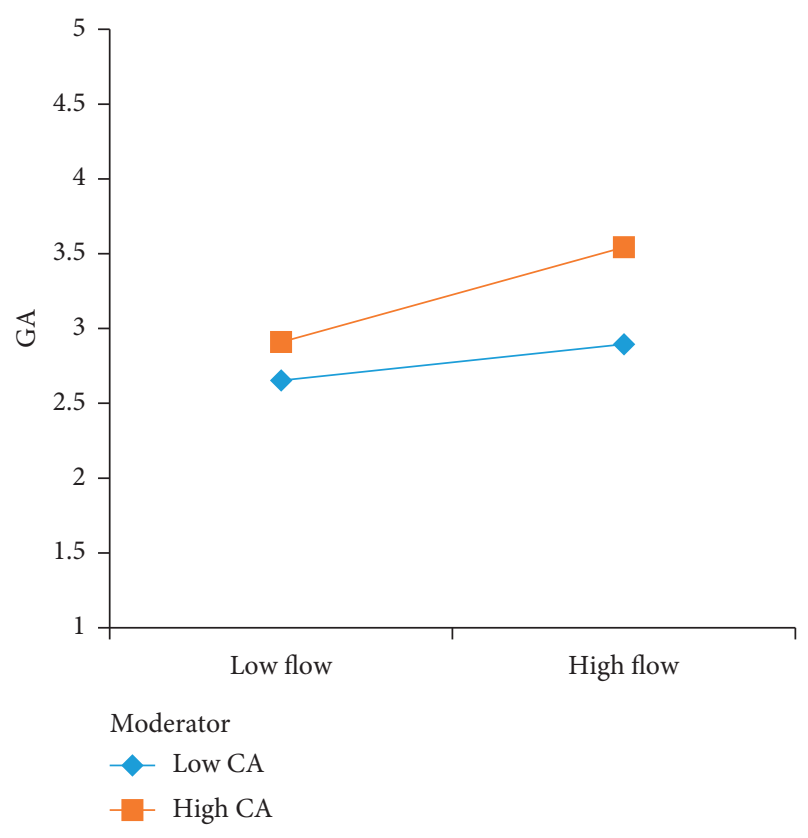

Figure 2: Interaction plot for cyber aggression over the association between flow experience and VR games addiction.

purpose as it can be seen that it creates high addictive behavior so all the policymakers and legislators and suppliers have their social responsibility and ethical responsibility to tackle the addiction in the VR products as this study also identify this issue. The entertainment industry is changing and adopting advanced technology like VR, so it is a need time that there should be a proper policy so the dark aspects of the entertainment industry through VR can also be tackled. As in this study, Cyber aggression is needed to study further as in this study; authors have found behavioral desire as a mediator and Cyber Aggression as a moderator has positive effects on addiction. Furthermore, theoretical and practical implications are discussed further in the section below.

6.1. Theoretical Implications. This research presented the scholarly literature with in-depth and beneficial contributions. First of all, this research is the first of its kind to understand the actions of VR game addiction. Previous studies have been used other variables whereas in this current study authors approach the gamers' behavioral intentions towards the VR-based Games specifically the addiction behavior. Furthermore, in this paper authors used the attributes of flow as proposed by (Cho) inquire and understand the stance of the users towards the VR-based games. Secondly, behavioral desire is taken as a mediator while explaining the addiction behavior. It is used to check the addictive behavior of gamers. It was not used before in any research where it was used with the game's addiction. Moreover, few researchers adopted addiction with the behavioral model. Previous papers results indicated that excessive use of games is highly risky for the health of the gamers not only physically but mentally [61]. While previous studies also concluded that flow has high influence on users' addiction behavior. For instance, flow in cognitive absorption has an adverse effect on the users' behavior. It can be both negative and positive from a gaming perspective. The feeling of flow online is appealing to gamers. Therefore, the ability to obtain the flow sensation may influence the pace and length of gaming and therefore be involved in the creation and maintenance of addictive behaviors [20,62]. Moreover, Sherry indicated that the chance to witness flow online may be a strong gaming motivator. Addiction is sometimes called a desire; the high desire has a high probability of addiction towards anything he wishes for. Likewise, previous papers also support the stance of the current paper, which suggested that flow has a beneficial impact on the games' addiction behavior on the users [63]. Moreover, previous papers also suggest that besides the addiction, there are serious physical health concerns for those who use games excessively [64]. In this current study, authors have used behavioral desire, whereas, in previous papers, authors did not find any evidence where behavior desire has been used specifically in the context of the game's addiction. Moreover, flow-based factors, i.e., cognitive absorption, enjoyment, and time distortion, have been used in the game's addiction, but no study found where it has been used in the context of VR-based game addiction. Therefore, it is worth mentioning that it is also the novelty of this current study. Furthermore, the purposed mediator (behavioral desire) partially mediates the proposed relation of flow to addiction. The study also concluded that Cyber aggression is a psychological perspective that strengthens the addictive behavior of the users in the case of VR. Authors also found that psychological constructs dominate in creating addiction among the users and push them to use it extensively.

6.2. Practical Implications. In this current study, the authors found that flow creates a high level of behavioral desires among the users. Similarly, previous papers suggested that flow has a significant role in game addiction. In addition, experts voiced significant questions about wellness and Internet gaming addiction. Online gaming addictions were reportedly causing mental health issues for gamers. In particular, the claim among children is that game addiction can influence learning and thinking. Similarly, the time and demographic use of VR games can be limited. VR applications can be used for information rather than extreme entertainment. As previous papers suggested that its games can be used to develop the skills among the students and youngsters, it can also be said that VR games need to be improved in the context of learning to develop the IQ level of youngsters and students specifically. VR application can revise the algorithms and it can be restricted to a specific time. If the users exceed the time limit, it can be shut down itself. Flow is revolving around the users' satisfaction. Similarly, from the analysis of the current study results, it is found that flow does affect the addiction behavior with the help of behavioral desire. Therefore, the quality of the VR games application can be improved to attract more users to capture the global market. For the attraction of the users, 
developers need to develop more exciting characters in the games and make them more realistic to the current world. Balakrishnan and Gri suggested it is difficult to maintain the consumer's commitment to the Internet; thus, advanced features need to be built to draw consumers and allow them to come back and play VR games with technical advances. Moreover, it can harm the users' behavioral desire, which may disturb users' daily behavior. It can be taken into consideration that it will not disturb the users' behavior. Therefore, lust full users may likely to have more experience towards VAD. Moreover, applications can be developing for psychological treatment, medical training assistance and can be used for the learning purpose only. Furthermore, VR-based applications can be designed competitively so that users can have more time and use their cognitive skills to enhance their IQ level and learn new techniques, too, later on, use in their daily life. It is always considered that computer games are mentally oriented, which enhances the users' skills, specifically competitive games. Moreover, game developers can restrict games with age factors as recently, the MPPOG (i.e., PUBG) has put some restrictions on the Under 18 users. In this restriction, users under 1are only allowed to play for 3 hours' maximum in 24 hours. It is also advised for the VR game developers to put stricter restrictions on the users so they will not get addicted to VR-based games. As mention above, VR applications can be enhancing the cognitive skills of the users by developing more brains using games rather than games that waste the time of the users.

6.3. Limitation and Conclusion. In this current study, the authors used the Cognitive-Behavioral model to scrutinize the user's addictive behavior towards VR-based games. In the current context, the authors found that flow has the loftiest probability for the admiring situation. Similarly, flow has shown a significant impact on the user's addiction behavior towards the VR game's addiction. Behavioral desire is also found to be the source of creating addiction among the users. Authors have some limitations while conducting this research which could lead to new and further studies. VR applications can be enhanced and also improved so that users can use them and also recommend them to others. VR should be used for academic and training purposes rather than entertainment. The authors also suggest that further studies can carry out on specific demographic and educational qualifications. In this paper, education did not study, but it is advised that further studies can be done to keep the education level of the users and it can also be divided into developed and underdeveloped nations. Other factors of flow can be studied with other types of game addiction. While mapping the Cyber aggression mediator role, it is found that it is not used before with any type of addiction. At the same time, the present study is the first to use cyber aggression in the context of VR-based game addiction. Furthermore, in this study, authors adopted a quantitative approach, while further researches can also adopt the qualitative approach as well for data collection and analysis.

\section{Data Availability}

Data will be available on request to the corresponding author.

\section{Disclosure}

Jing Yuan, Xuesong Zhai, and Fahad Asmi should be considered as the co-first authors.

\section{Conflicts of Interest}

The authors declare no conflicts of interest.

\section{Authors' Contributions}

Jing Yuan, Xuesong Zhai, and Fahad Asmi contributed equally to this work.

\section{Acknowledgments}

This research work was supported by the National Social Science Fund of China (Grant ID: 17BXW034) and the Youth Foundation of Humanities and Social Sciences Project of the Ministry of Education in China (Grant ID: 20YJC880118).

\section{References}

[1] D. M. Shafer, C. P. Carbonara, and M. F. Korpi, "Factors affecting enjoyment of virtual reality games: a comparison involving consumer-grade virtual reality technology," Games for Health Journal, vol. 8, no. 1, pp. 15-23, 2019.

[2] T. Hartmann and J. Fox, "Entertainment in virtual reality and beyond: the influence of embodiment, Co-location, and cognitive distancing on users' entertainment experience tilo," in The Oxford Handbook of Entertainment TheoryOxford University Press, Oxford, UK, 2020.

[3] M. Wood, G. Wood, and M. Balaam, "They're just tixel pits, man," in Proceedings of the 2017 CHI Conference on Human Factors in Computing Systems, pp. 5439-5451, New York, NY, USA, May 2017.

[4] J. Zenor, "Sins of the flesh? Obscenity law in the era of virtual reality," Communication Law and Policy, vol. 19, no. 4, pp. 563-589, 2014.

[5] K. E. Jung and H. Lee, "The adoption of virtual reality devices: the technology acceptance model integrating enjoyment, social interaction, and strength of the social ties," Telematics and Informatics, vol. 39, pp. 37-48, 2018.

[6] Z. Merchant, E. T. Goetz, L. Cifuentes, W. Keeney-Kennicutt, and T. J. Davis, "Effectiveness of virtual reality-based instruction on students' learning outcomes in K-12 and higher education: a meta-analysis," Computers \& Education, vol. 70, pp. 29-40, 2014.

[7] J. Parong and R. E. Mayer, "Cognitive consequences of playing brain-training games in immersive virtual reality," Applied Cognitive Psychology, vol. 34, no. 1, pp. 29-38, 2020.

[8] Y. Jang and E. Park, "An adoption model for virtual reality games: the roles of presence and enjoyment," Telematics and Informatics, vol. 42, Article ID 101239, 2019.

[9] Digi-Capital Augmented/Virtual Reality Revenue Forecast Revised to Hit $\$ 120$ Billion by 2020, https://www.digi-capital. com/news/2020/08/the-ar-vr-ecosystem-are-we-there-yet/. 
[10] A. Keizer, A. A. Cuperus, J. A. W. Teijink, A. W. M. Evers, I. J. M. van der Ham, and M. M. L. van den Houten, "Manipulating spatial distance in virtual reality: effects on treadmill walking performance in patients with intermittent claudication," Computers in Human Behavior, vol. 79, pp. 211-216, 2017.

[11] J. W. B. Elsey, K. van Andel, R. B. Kater, I. M. Reints, and M. Spiering, "The impact of virtual reality versus 2D pornography on sexual arousal and presence," Computers in Human Behavior, vol. 97, pp. 35-43, 2019.

[12] D. Marinova, K. de Ruyter, M.-H. Huang, M. L. Meuter, and G. Challagalla, "Getting smart," Journal of Service Research, vol. 20, no. 1, pp. 29-42, 2017.

[13] M. S. Davis and M. Csikszentmihalyi, "Beyond boredom and anxiety: the experience of play in work and games," Contemporary Sociology, vol. 6, no. 2, p. 197, 1977.

[14] Y. Fu and Q. Li, "Flow theory in the interactive design of educational games," Int. J. Contemp. Humanit., 2020.

[15] J. Nakamura and M. Csikszentmihalyi, "The concept of flow," in Handbook of Positive Psychology, pp. 89-105, Oxford University Press, Oxford, UK, 2002.

[16] Y. Yan, R. M. Davison, and C. Mo, "Employee creativity formation: the roles of knowledge seeking, knowledge contributing and flow experience in Web 2.0 virtual communities," Computers in Human Behavior, vol. 29, no. 5, pp. 1923-1932, 2013.

[17] J. Hamari, D. J. Shernoff, E. Rowe, B. Coller, J. Asbell-clarke, and T. Edwards, "Challenging games help students learn: an empirical study on engagement, flow and immersion in gamebased learning," Computers in Human Behavior, vol. 54, pp. 170-179, 2016.

[18] J. Matute-Vallejo and I. Melero-Polo, "Understanding online business simulation games: the role of flow experience, perceived enjoyment and personal innovativeness," Australasian Journal of Educational Technology, vol. 35, no. 3, pp. 71-85, 2019.

[19] E. Hu, V. Stavropoulos, A. Anderson, M. Scerri, and J. Collard, "Internet gaming disorder: feeling the flow of social games," Addictive Behaviors Reports, vol. 9, Article ID 100140, 2019.

[20] M. D. Griffiths, D. J. Kuss, and D. L. King, "Video game addiction: past, present and future," Current Psychiatry Reviews, vol. 44, 2012.

[21] D. J. Kuss and M. D. Griffiths, "Internet addiction in students: prevalence and risk factors," Journal of Chemical Information and Modeling, vol. 53, pp. 1689-1699, 2013.

[22] M. Peeters, I. Koning, and R. van den Eijnden, "Predicting Internet Gaming Disorder symptoms in young adolescents: a one-year follow-up study," Computers in Human Behavior, vol. 80, pp. 255-261, 2018.

[23] N. Zilberman, G. Yadid, Y. Efrati, and Y. Rassovsky, "Negative and positive life events and their relation to substance and behavioral addictions," Drug and Alcohol Dependence, vol. 204, p. 107562, 2019.

[24] C. Varo, A. Murru, E. Salagre et al., "Behavioral addictions in bipolar disorders: a systematic review," European Neuropsychopharmacology, vol. 29, no. 1, pp. 76-97, 2019.

[25] J. Burrell, "Raising the stakes: E-sports and the professionalization of computer games," in Contemporary Sociology, pp. 623-624, MIT Press, Cambridge, MA, USA, 2012.

[26] M. E. Portman, A. Natapov, and D. Fisher-Gewirtzman, "To go where no man has gone before: virtual reality in architecture, landscape architecture and environmental planning,"
Computers, Environment and Urban Systems, vol. 54, pp. 376-384, 2015.

[27] E. K. Yuen, E. M. Goetter, M. J. Stasio et al., "A pilot of acceptance and commitment therapy for public speaking anxiety delivered with group videoconferencing and virtual reality exposure," Journal of Contextual Behavioral Science, vol. 12, pp. 47-54, 2019.

[28] F. Ke, M. Pachman, and Z. Dai, "Investigating educational affordances of virtual reality for simulation-based teaching training with graduate teaching assistants," Journal of Computing in Higher Education, vol. 32, no. 3, pp. 607-627, 2020.

[29] H. Yang, J. Yu, H. Zo, and M. Choi, "User acceptance of wearable devices: an extended perspective of perceived value," Telematics and Informatics, vol. 33, no. 2, pp. 256-269, 2016.

[30] F. D. Davis, "Perceived usefulness, perceived ease of use, and user acceptance of information technology," MIS Quarterly, vol. 13, no. 3, p. 319, 1989.

[31] R. Agarwal and E. Karahanna, “Time flies when you're having fun: cognitive absorption and beliefs about information technology usage," MIS Quarterly, vol. 24, no. 4, pp. 665-694, 2000.

[32] V. Venkatesh and F. D. Davis, "A theoretical extension of the technology acceptance model: four longitudinal field studies," Management Science, vol. 46, no. 2, pp. 186-204, 2000.

[33] V. Vankatesh, M. G. Morris, M. Hall, G. B. Davis, F. D. Davis, and S. M. Walton, "User acceptance of information technology: toward a unified view 1," MIS Quarterly, vol. 27, no. 3, pp. 425-478, 2003.

[34] V. Venkatesh, Y. L. Thong, and X. Xu, "Consumer acceptance and use of information technology: extending the unified theory of acceptance and use of technology," MIS Quarterly, vol. 36, no. 1, pp. 157-178, 2012.

[35] R. A. Davis, "Cognitive-behavioral model of pathological Internet use," Computers in Human Behavior, 2001.

[36] O. Turel and A. Serenko, "Developing a (bad) habit: antecedents and adverse consequences of social networking website use habit," in Proceedings of the 17th Americas Conference on Information Systems 2011, AMCIS, Detroit, MI, USA, August 2011.

[37] X. Zheng and M. K. O. Lee, "Excessive use of mobile social networking sites: negative consequences on individuals," Computers in Human Behavior, vol. 65, pp. 65-76, 2016.

[38] M. Brand, C. Laier, and K. S. Young, "Internet addiction: coping styles, expectancies, and treatment implications," Frontiers in Psychology, vol. 5, pp. 1-14, 2014.

[39] C. Wang, M. K. O. Lee, and Z. Hua, "A theory of social media dependence: evidence from microblog users," Decision Support Systems, vol. 69, pp. 40-49, 2015.

[40] M. Csikszentmihalyi, Beyond Boredom and Anxiety, JosseyBass Inc., San Francisco, CA, USA, 2000.

[41] M. Csikszentmihalyi, "Happiness and creativity: going with the flow," Futurist, 1997.

[42] M. Cziksentmihalyi, "Flow: the psychology of optimal experience," Academy of Management Review, vol. 16, pp. 636-640, 1990.

[43] M. A. Csikszentmihalyi, "Theoretical model for enjoyment," in Beyond Boredom and AnxietyJossey-Bass Inc., San Francisco, CA, USA, 1975.

[44] S.-H. Im and S. Varma, "Distorted time perception during flow as revealed by an attention-demanding cognitive task," Creativity Research Journal, vol. 30, no. 3, pp. 295-304, 2018.

[45] E. Ghazali, D. S. Mutum, and M.-Y. Woon, "Exploring player behavior and motivations to continue playing Pokémon GO," 
Information Technology \& People, vol. 32, no. 3, pp. 646-667, 2019.

[46] X. Gong, K. Z. K. Zhang, C. M. K. Cheung, C. Chen, and M. K. O. Lee, "Alone or together? Exploring the role of desire for online group gaming in players' social game addiction," Information \& Management, vol. 56, no. 6, Article ID 103139, 2019.

[47] S. Sanjamsai and D. Phukao, "Flow experience in computer game playing among Thai university students," Kasetsart Journal of Social Sciences, vol. 39, no. 2, pp. 175-182, 2018.

[48] K. C. Berridge and T. E. Robinson, "Liking, wanting, and the incentive-sensitization theory of addiction," American Psychologist, vol. 71, no. 8, pp. 670-679, 2016.

[49] T. Rose, M. Barker, C. Maria Jacob et al., "A systematic review of digital interventions for improving the diet and physical activity behaviors of adolescents," Journal of Adolescent Health, vol. 61, no. 6, pp. 669-677, 2017.

[50] O. Turel and H. Qahri-Saremi, "Problematic use of social networking sites: antecedents and consequence from a dualsystem theory perspective," Journal of Management Information Systems, vol. 33, no. 4, pp. 1087-1116, 2016.

[51] M. F. Wright, "Parental mediation, cyberbullying, and cybertrolling: the role of gender," Computers in Human Behavior, vol. 71, pp. 189-195, 2017.

[52] F. Pereira, B. H. Spitzberg, and M. Matos, "Cyber-harassment victimization in Portugal: prevalence, fear and help-seeking among adolescents," Computers in Human Behavior, vol. 62, pp. 136-146, 2016.

[53] E. Larrañaga, S. Yubero, A. Ovejero, and R. Navarro, "Loneliness, parent-child communication and cyberbullying victimization among Spanish youths," Computers in Human Behavior, vol. 65, pp. 1-8, 2016.

[54] A. Vale, F. Pereira, M. Gonçalves, and M. Matos, "Cyberaggression in adolescence and internet parenting styles: a study with victims, perpetrators and victim-perpetrators," Children and Youth Services Review, vol. 93, pp. 88-99, 2018.

[55] J.-B. Liu and S. N. Daoud, "Number of spanning trees in the sequence of some graphs," Complexity, vol. 2019, Article ID 4271783, 22 pages, 2019.

[56] J. Cao, J.-B. Liu, and S. Wang, "Resistance distances in corona and neighborhood corona networks based on Laplacian generalized inverse approach," Journal of Algebra and its Applications, vol. 18, no. 3, Article ID 1950053, 2019.

[57] J. C. Anderson and D. W. Gerbing, "Structural equation modeling in practice: a review and recommended two-step approach," Psychological Bulletin, vol. 103, pp. 411-423, 1998.

[58] R. C. Maccallum, M. W. Browne, and H. M. Sugawara, "Power analysis and determination of sample size for covariance structure modeling," Psychological Methods, vol. 1, no. 2, pp. 130-149, 1996.

[59] J. F. Hair, W. C. Black, B. J. Babin, and R. E. Anderson, Multivariate Data Analysis, CRC Press, Boca Raton, FL, USA, 7th edition, 2014.

[60] P. M. Podsakoff, S. B. MacKenzie, J.-Y. Lee, and N. P. Podsakoff, "Common method biases in behavioral research: a critical review of the literature and recommended remedies," Journal of Applied Psychology, vol. 88, no. 5, pp. 879-903, 2003.

[61] P. Dullur and P. Hay, "Problem internet use and internet gaming disorder: a survey of health literacy among psychiatrists from Australia and New Zealand," Australasian Psychiatry, vol. 25, no. 2, pp. 140-145, 2017.

[62] B. L. M. Adams, V. Stavropoulos, T. L. Burleigh, L. W. L. Liew, C. L. Beard, and M. D. Griffiths, "Internet gaming disorder behaviors in emergent adulthood: a pilot study examining the interplay between anxiety and family cohesion," International Journal of Mental Health and Addiction, vol. 17, pp. 828-844, 2018.

[63] X. Zhai, F. Asmi, R. Zhou et al., "Investigating the mediation and moderation effect of students' addiction to virtual reality games: a perspective of structural equation modeling," Discrete Dynamics in Nature and Society, vol. 2020, Article ID 5714546, 13 pages, 2020.

[64] J. Gackenbach, D. Wijeyaratnam, and C. Flockhart, The Video Gaming Frontier, Elsevier, Amsterdam, Netherlands, 2017. 